\title{
Hepatotoxicity induced by clozapine: a case report and review of literature
}

\author{
This article was published in the following Dove Press journal: \\ Neuropsychiatric Disease and Treatment \\ 26 August 2014 \\ Number of times this article has been viewed
}

\author{
Ana Isabel Wu Chou' \\ Mong-Liang Lu $\mathrm{u}^{1,2}$ \\ Winston W Shen ${ }^{1,2}$ \\ 'Department of Psychiatry, Wan-Fang \\ Hospital, Taipei Medical University, \\ ${ }^{2}$ Department of Psychiatry, School \\ of Medicine, Taipei Medical University, \\ Taipei, Taiwan
}

\begin{abstract}
Clozapine is an effective antipsychotic drug but is associated with serious side effects. Most treatment guidelines give no clear recommendations on regular monitoring of liver function tests, even though up to $60 \%$ of patients experience elevations in hepatic transaminases, with $15 \%$ to $30 \%$ experiencing an elevation two to three times greater than normal. Though elevations in liver function tests are often transient and asymptomatic, there are many reported cases of clozapine-induced hepatotoxicity, with damage to the liver, involvement of multiple organs, and even fulminant liver failure arising with moderate clozapine doses. This case report describes a Chinese woman who developed hepatotoxicity on a low dose of clozapine, and reviews the relevant literature.
\end{abstract}

Keywords: hepatitis, antipsychotic adverse effects, drug-induced liver injury

\section{Introduction}

Clozapine is an atypical antipsychotic introduced in the 1970 s and used for the treatment of psychosis. Its use is reserved as a second-line treatment drug for refractory schizophrenia because of its safety profile - it is associated with fatal agranulocytosis that requires a strict white blood cell monitoring and several gastrointestinal adverse effects, such as constipation, ileus and hepatitis. ${ }^{1}$ Clozapine-induced hepatic impairment has received limited attention in the literature, and no clear recommendations have been given to address this. Blood monitoring for liver function is not mandatory as is the case for agranulocytosis, though up to $60 \%$ of patients may experience an increase in liver enzyme levels, ${ }^{2}$ with $15 \%-30 \%$ of patients experiencing an elevation two to three times the normal value. ${ }^{3}$ This case report describes hepatotoxicity associated with low-dose clozapine in a Chinese woman and reviews the pertinent literature.

\section{Case report}

Ms Z was a 45-year-old widow with schizophrenia who had received various antipsychotic drugs, including risperidone, olanzapine, haloperidol, and paliperidone, since the age of 34 . She had no history of systemic diseases or substance use. She also avoided caffeinated drinks, such as Chinese tea and coffee as they caused her palpitations and insomnia. Despite the use of many different antipsychotics, her psychotic symptoms remained resistant to treatment. On admission to hospital, she was put on a cross-titration, from olanzapine to clozapine. Baseline liver function tests (LFTs) and complete blood count results were within normal limits. Twelve days later, the patient complained of headache and malaise while on a daily dose of clozapine $125 \mathrm{mg}$ and olanzapine $2.5 \mathrm{mg}$. She had fever $\left(38.7^{\circ} \mathrm{C}\right)$, elevated aspartate $(176 \mathrm{IU} / \mathrm{L})$ and alanine aminotransferase levels (181 IU/L), white blood cell count $\left(13.9 \times 10^{3}\right.$ cells $\left./ \mu \mathrm{L}\right)$, and C-reactive protein level $(5.37 \mathrm{mg} / \mathrm{dL})$. Her serum bilirubin level was normal.
Correspondence: Mong-Liang Lu Department of Psychiatry, Wan-Fang Hospital, No III, Section 3, Hsing Long Road,Taipei I I6, Taiwan Tel +886229307930 ext 5396।

Email monglianglu@gmail.com 
The findings of her abdominal ultrasound were compatible with drug-induced hepatitis, and her serologic test results for hepatitis A, B, and C were all negative. She was diagnosed with clozapine-induced hepatitis, and her LFTs returned to normal 2 weeks after the drug was discontinued. When her LFTs returned to normal, the patient agreed to a clozapine rechallenge since her hallucinations remained distressing. She was given clozapine at a starting dose of $25 \mathrm{mg}$ in the evening and slowly titrated upwards under close monitoring for abnormal physical examination and liver function. This time, at a dose of clozapine $100 \mathrm{mg}$ in the evening, the patient started to complain of fever and generalized weakness. Her body temperature was $38.2^{\circ} \mathrm{C}$, and her LFT result showed elevated alanine aminotransferase (69 IU/L) and a normal aspartate aminotransferase (37 IU/L). After immediate discontinuation of clozapine, her LFT levels continued to escalate in the following week, even though she became asymptomatic, afebrile, and her physical examination was normal. LFT results at the time of her discharge remained slightly high but returned to baseline levels in the following month.

\section{Discussion}

Our diagnosis of clozapine-induced hepatitis is one of exclusion that was based on the onset of symptoms after clozapine initiation and remission with cessation of the drug, and confirmed by a subsequent clozapine rechallenge. A score of 9 or greater ( 9 in our case) in the Naranjo Adverse Drug Reaction Probability Scale ${ }^{4}$ showed that there was a definite relationship between the adverse effect (hepatitis) and clozapine. The etiology results from either a metabolic idiosyncrasy or from an immunoallergic reaction. ${ }^{3}$ We postulate that our patient had an idiosyncratic hepatotoxic drug reaction, given her lack of eosinophilia. Our patient shared some features with reported cases in the literature: elevations of both transaminases, and normalization of laboratory results at about 1 month after cessation of clozapine. However, she is unique in that she developed symptoms of hepatitis shortly after starting treatment and at lower doses than most other reported cases.

Most drug-induced liver toxicities result from injury to hepatocytes and present a clinical picture that resembles viral hepatitis, where, like in our case, patients develop malaise, elevated LFTs, and sometimes, jaundice. ${ }^{5}$ In the case of clozapine, hepatic impairments range from the most common presentation of asymptomatic aminotransferase elevations to cytolytic or cholestatic hepatitis, toxic hepatitis (like in our case), and even fulminant hepatitis, depending on the type of liver injury that predominates. ${ }^{6,7-16}$ Though elevations of liver enzymes with clozapine are usually transient and resolve spontaneously in about half of patients, without having to reduce their clozapine dose,${ }^{17}$ this was not the case for our patient. Her clinical symptoms and abnormal LFTs persisted until clozapine was completely discontinued. The elevations have been reported to be dose-dependent and to develop, usually, at medium-range doses of clozapine (200-400 mg) ${ }^{18}$ but our patient developed hepatitis at a much lower dose. One possible explanation for our patient's sensitivity to clozapine toxicity is that Asians have a reduced cytochrome P450 1A2 (CYP1A2) activity; the enzyme mainly responsible for the metabolism of clozapine. ${ }^{19}$ This could also explain why she developed hepatitis shortly after initiation of treatment instead of a more delayed onset, as documented in the literature ( 5 weeks to a few months into treatment). ${ }^{17}$ It is worthwhile noting that she was also particularly sensitive to the side effects of caffeine, a substrate used for the measurement of CYP1A2 activity $^{20}$ - a reduced CYP1A2 activity can also explain her intolerance to caffeine. Other than clozapine dose, plasma concentrations have been reported useful in predicting liver damage, ${ }^{17}$ but this examination was not available at our facility.

The exact incidence of clinically significant clozapineinduced hepatic impairment is unknown, but evidence of its hepatotoxicity is supported by a PubMed search showing cases with clozapine-induced hepatitis; multiorgan involvement including pleuritis; serositis; and even fulminant hepatic failure leading to death. ${ }^{6,9-10}$ Clinical symptoms, such as malaise, fever, rash, and jaundice should prompt measurements of LFTs, and discontinuation of clozapine is warranted when the elevations of LFTs are beyond three times the normal upper limit value. ${ }^{21}$ It is also important to take into consideration that schizophrenia patients may have higher baseline LFTs because of a higher prevalence of hepatitis C. ${ }^{22}$

The hepatotoxic effects of clozapine have received much less attention in the literature than its cardiometabolic and hematologic counterparts. Most prescribing guidelines give no clear recommendations for the monitoring of liver enzymes, with the exception of the Maudsley guidelines, which suggest yearly LFTs after initial baseline values are determined. ${ }^{23}$ Some have suggested regular monitoring of LFTs, ${ }^{5,24}$ but this may result in increased number of patients being taken off clozapine unnecessarily. We therefore think that careful observation of the patient's clinical symptoms is more important than regular monthly or biannual measurement of LFTs. As seen in our patient and in the other cases reported in the literature, patients with normal baseline LFTs 
may either experience unpredictable delayed hepatitis or become symptomatic shortly after starting the drug (within 1-2 weeks in our case). Based on the information in the published papers and this reported case, we suggest that 1) LFTs should be obtained before initiating clozapine therapy and obtained on an "as needed" basis, depending on patients' clinical symptoms (jaundice, fever, rash, and malaise); and 2) patients with reduced metabolism of clozapine, such as Asians and geriatric patients, may benefit from lower doses and slower upwards titration of clozapine, to avoid the hepatotoxic effects of clozapine. Further investigation is warranted to establish newer guidelines for the prevention of clozapine toxicities to the liver.

\section{Disclosure}

The authors report no conflicts of interest in this work.

\section{References}

1. Cohen D, Bogers JP, van Dijk D, Bakker B, Schulte PF. Beyond white blood cell monitoring: screening in the initial phase of clozapine therapy. J Clin Psychiatry. 2012;73(10):1307-1312.

2. Gaertner HJ, Fischer E, Hoss J. Side effects of clozapine. Psychopharmacology (Berl). 1989;99 Suppl:S97-S100.

3. Hummer M, Kurz M, Kurzthaler I, Oberbauer H, Miller C, Fleischhacker WW. Hepatotoxicity of clozapine. J Clin Psychopharmacol. 1997;17(4):314-317.

4. US National Library of Medicine. LiverTox database. Available from: http://livertox.nih.gov/Naranjoassessment.pdf. Accessed August 5, 2014.

5. Lee WM. Drug-induced hepatotoxicity. $N$ Engl J Med. 2003;349(5): 474-485.

6. Macfarlane B, Davies S, Mannan K, Sarsam R, Pariente D, Dooley J. Fatal acute fulminant liver failure due to clozapine: a case report and review of clozapine-induced hepatotoxicity. Gastroenterology. 1997; 112(5):1707-1709.

7. Kellner M, Wiedemann K, Krieg JC, Berg PA. Toxic hepatitis by clozapine treatment. Am J Psychiatry. 1993;150:985-986.

8. Erdogan A, Kocabasoglu N, Yalug I, Ozbay G, Senturk H. Management of marked liver enzyme increase during clozapine treatment: a case report and review of the literature. Int J Psychiatry Med. 2004;34(1): $83-89$.
9. Thatcher GW, Cates M, Bair B. Clozapine-induced toxic hepatitis. Am J Psychiatry. 1995;152(2):296-297.

10. Luo D, McColl P, Walmsley R. Acute onset of ascites with clozapineinduced hepatitis. Intern Med J. 2007;37(3):204-205.

11. Brown CA, Telio S, Warnock CA, Wong AH. Clozapine toxicity and hepatitis. J Clin Psychopharmacol. 2013;33(4):570-571.

12. Keane S, Lane A, Larkin T, Clarke M. Management of clozapine-related hepatotoxicity. J Clin Psychopharmacol. 2009;29(6):606-607.

13. Chang A, Krygier DS, Chatur N, Yoshida EM. Clozapine-induced fatal fulminant hepatic failure: a case report. Can J Gastroenterol. 2009; 23(5):376-378.

14. Thompson J, Chengappa KN, Good CB, et al. Hepatitis, hyperglycemia, pleural effusion, eosinophilia, hematuria and proteinuria occurring early in clozapine treatment. Int Clin Psychopharmacol. 1998;13(2): 95-98.

15. Worrall R, Wilson A, Cullen M. Dystonia and drug-induced hepatitis in a patient treated with clozapine. Am J Psychiatry. 1995;152(4): 647-648.

16. Kang SH, Lee J. Eosinophilia, pleural effusion, hepatitis, and jaundice occurring early in clozapine treatment. Clin Psychopharmacol Neurosci. 2013;11(2):103-105.

17. Gaertner I, Altendorf K, Batra A, Gaertner HJ. Relevance of liver enzyme elevations with four different neuroleptics: a retrospective review of 7,263 treatment courses. J Clin Psychopharmacol. 2001; 21(2):215-222.

18. Marinkovic D, Timotijevic I, Babinski T, Totic S, Paunovic VR. The side-effects of clozapine: a four year follow-up study. Prog Neuropsychopharmacol Biol Psychiatry. 1994;18(3):537-544.

19. Subramaniam M, Ng C, Chong SA, et al. Metabolic differences between Asian and Caucasian patients on clozapine treatment. Hum Psychopharmacol. 2007;22(4):217-222.

20. Ozdemir V, Kalow W, Posner P, et al. CYP1A2 activity as measured by a caffeine test predicts clozapine and active metabolite steady-state concentration in patients with schizophrenia. J Clin Psychopharmacol. 2001;21(4):398-407.

21. Nielsen J, Correll CU, Manu P, Kane JM. Termination of clozapine treatment due to medical reasons: when is it warranted and how can it be avoided? J Clin Psychiatry. 2013;74(6):603-613; quiz 613.

22. Freudenreich O, Gandhi RT, Walsh JP, Henderson DC, Goff DC. Hepatitis C in schizophrenia: screening experience in a communitydwelling clozapine cohort. Psychosomatics. 2007;48(5):405-411.

23. Taylor D, Paton C, Shitij K. The Maudsley Prescribing Guidelines. 10th ed. London: Informa Healthcare; 2011

24. Markowitz JS, Grinberg R, Jackson C. Marked liver enzyme elevations with clozapine. J Clin Psychopharmacol. 1997;17(1):70-71.
Neuropsychiatric Disease and Treatment

\section{Publish your work in this journal}

Neuropsychiatric Disease and Treatment is an international, peerreviewed journal of clinical therapeutics and pharmacology focusing on concise rapid reporting of clinical or pre-clinical studies on a range of neuropsychiatric and neurological disorders. This journal is indexed on PubMed Central, the 'PsycINFO' database and CAS,

\section{Dovepress}

and is the official journal of The International Neuropsychiatric Association (INA). The manuscript management system is completely online and includes a very quick and fair peer-review system, which is all easy to use. Visit http://www.dovepress.com/testimonials.php to read real quotes from published authors. 